\title{
COMMENTARY
}

\section{Traditional transfusion practices are changing}

\author{
John B Holcomb* \\ See related research by Schochl et al., http://ccforum.com/content/14/2/R55
}

\begin{abstract}
Schochl and co-authors have described a 5-year retrospective study that outlines a novel, important and controversial transfusion concept in seriously injured trauma patients. Traditionally, clinicians have been taught to use a serial approach, resuscitating hypovolemic trauma patients with a form of crystalloid or colloid, followed by red blood cells (RBCs), then fresh frozen plasma (FFP), and lastly platelets. The data supporting this widely accepted approach are remarkably weak. Conversely, Schochl and colleagues, in an innovative, retrospective study, describe the use of fibrinogen concentrate, plasma complex concentrate, RBCs, FFP, and platelets driven by a thromboelastometry-based algorithm. Finally, it appears that transfusion therapy is becoming driven by physiology.
\end{abstract}

The data presented by Schochl and colleagues will be seen as intriguing, important, innovative, and controversial [1]. This paper builds on work by Dr Detmer Fries, published in a swine injury model in 2006 [2,3]. However, as with all retrospective studies, caution must be exercised before widespread adoption. The usual concerns apply as there is no control group, the data supporting the thromboelastometry goal-directed algorithm are not presented, and the risks of using and combining fibrinogen concentrates and plasma complex concentrates (PCCs) in trauma patients are unknown. Preclinical and clinical evidence to answer these questions is lacking and should be investigated.

With regards to the study by Schochl and colleagues, I am concerned with the comparison of mortality rates in the small numbers of seriously injured patients collected over 5 years to that predicted by the trauma injury severity score (TRISS) and by the revised injury severity

*Correspondence: John.Holcomb@uth.tmc.edu

Center for Translational Injury Research, University of Texas health Science Center, 6410 Fannin, Suite 1100, Houston, TX 77030, USA classification (RISC) score. It is very easy for such small data sets to suffer significant statistical problems when attempting to match injuries and initial physiology. It would have been preferable to at least construct a before and after design. Several questions are apparent: when the thromboelastometry was repeated, did the test results change (improve?) after transfusion of the proscribed agent? What was the timing of the fibrinogen and PCC concentrates in relation to red blood cells (RBCs)? How often was the fibrinogen or PCC given before the RBCs? How did mortality change over time, as the authors became more comfortable with their alternative resuscitation strategy?

Despite these and many more questions, I sincerely congratulate the authors on forging ahead and introducing a novel resuscitation approach. The issues inherent in this retrospective study (and in every one of the recently published retrospective transfusion studies, including ours [4]) are significant and will only be resolved when prospective studies are finally performed. As an aside, this standard comment leads me to wonder why we must have level I data to change traditional practice, when the current transfusion traditions are based on small, uncontrolled, rarely read, retrospective studies utilizing blood products no longer available. Tradition is recognized as the hardest thing to change, and the recent and now numerous transfusion studies in seriously injured patients are arguably leading the way in a wholesale revolution in transfusion medicine. It seems that physiology is starting to take precedence over tradition in this area, and other specialties are taking notice.

We now recognize that fully one-third of transfused patients are coagulopathic. For years, in seriously injured trauma patients suffering hemorrhagic shock, we first gave multiple varieties of salt solutions, followed by RBCs. There was an ongoing controversy about crystalloid versus colloid; these resuscitation fluids increase coagulation problems and neither increase oxygen delivery. Only after liters of these fluids were transfused were components that both increased intravascular volume and helped reverse coagulopathy finally delivered. Now, many centers are giving early and increased amounts of plasma proteins and platelets. At our center we more frequently give plasma before $\mathrm{RBCs}$ in our 
seriously injured trauma patients that suffer hemorrhagic shock. Anecdotally, this change in practice has been associated with less bleeding, improved survival, decreased edema and lowered multiple organ failure rates. The mechanism accounting for these clinical observations remains to be elucidated $[5,6]$. We feel that many of these products not only replace coagulation factors, facilitating early cessation of bleeding, and provide effective volume resuscitation, but more importantly stabilize the endothelium, reverse the early coagulopathy of trauma, reverse endothelial permeability, decrease edema and repair the endothelium, thus preventing early onset of multiple organ failure related to resuscitation injury. The thousands of proteins present in platelets and plasma certainly 'do more than' just replace the few coagulation proteins we commonly measure.

The transfusion method of Schochl and colleagues appears to be more physiologic and data driven when compared to the tradition-motivated approach to resuscitation of the severely injured trauma patient in hemorrhagic shock. More studies like this will soon see the light of publication and form the basis for a revolution in transfusion therapy over the next decade. I think that commercial entities should take note, as their approach will certainly open new markets and opportunities.

Current blood banks are largely focused on logistical issues of shelf life, avoiding disease transmission, and the immunologic consequences of liquid transfusion. They have been very successful in managing these issues. However, there have been very few well designed studies over the past 30 years in the transfusion literature describing any clinical improvements after transfusion in trauma patients. No quality data from studies in trauma patients are available for current blood products. Amazingly, there is no requirement to have clinical outcome data when modifications to currently approved blood products are introduced. Injury has been recognized as causing more than 5 million deaths worldwide and is listed as a major global issue by the WHO [7]. It is time for blood banks to evolve [8]. It is easy to anticipate a separation of emergency transfusion in rapidly bleeding patients from the traditional blood bank over the next decade, with dried blood products/proteins utilized in a point of care mode, stored in the clinical areas where the patients are cared for (including the pre-hospital environment), and resuscitation based upon laboratory data available within minutes that guide protein-specific infusion. It will be nice to only transfuse what is needed, based on level I data, finally balancing risk and benefit in a data-driven fashion for the benefit of our patients. The paper by Schochl and colleagues is a step in that direction.

\section{Abbreviations}

$\mathrm{PCC}=$ plasma complex concentrate; $\mathrm{RBC}=$ red blood cell.

Competing interests

The author declares that he has no competing interests.

Published: 1 June 2010

\section{References}

1. Schoechl H, Nienaber U, Jambor C, Hofer G, Scharbert G, Voelckel W, KozekLangenecker S, Solomon C: Goal-directed coagulation management of major trauma patients using rotation thromboelastometry (ROTEM $\left.{ }^{\oplus}\right)$ guided administration of fibrinogen and prothrombin complex concentrate. Crit Care 2010, 14:R55.

2. Fries $D$, Innerhofer $P$, Schobersberger W: Time for changing coagulation management in trauma-related massive bleeding. Curr Opin Anaesthesiol 2009, 22:267-274.

3. Fries D, Haas T, Klingler A, StreifW, Klima G, Martini J, Wagner-Berger H, Innerhofer P: Efficacy of fibrinogen and prothrombin complex concentrate used to reverse dilutional coagulopathy - a porcine model. Br J Anaesth 2006, 97:460-467.

4. Holcomb JB, Wade CE, Michalek JE, Chisholm GB, Zarzabal LA, Schreiber MA, Gonzalez EA, Pomper GJ, Perkins JG, Spinella PC, Williams KL, Park MS: Increased plasma and platelet to red blood cell ratios improves outcome in 466 massively transfused civilian trauma patients. Ann Surg 2008, 248:447-458.

5. Pati S, Matijevic M, Doursout,M, Ko T, Cao Y, Deng X, Kozar R, Hartwell E, Conyers J, Holcomb JB: The protective effects of fresh frozen plasma (FFP) on vascular endothelial permeability, coagulation, and resuscitation after hemorrhagic shock are time dependent and diminish between day 0 and day 5 after thaw. J Trauma 2010, in press.

6. Chesebro BB, Rahn P, Carles M, Esmon CT, Xu J, Brohi K, Frith D, Pittet JF, Cohen MJ: Increase in activated protein $C$ mediates acute traumatic coagulopathy in mice. Shock 2009, 32:659-665.

7. Peden M, McGee K, Sharma G: The Injury Chart Book: a Graphical Overview of the Global Burden of Injuries. Geneva: World Health Organization; 2002 [http://www.who.int/violence_injury_prevention/publications/other_injury/ chartb/en]

8. Johansson PI: The blood bank: from provider to partner in treatment of massively bleeding patients. Transfusion 2007, 47(2 Suppl):176S-181S; discussion 182S-183S.

doi:10.1186/cc9009

Cite this article as: Holcomb JB: Traditional transfusion practices are changing. Critical Care 2010, 14:162. 